\title{
Impact of Financial Literacy on the Behavioral Biases of Individual Stock Investors: Evidence from Borsa Istanbul
}

\begin{abstract}
Sinem Ateş ${ }^{\mathrm{a}}$
Ali Coşkun ${ }^{\mathrm{b}}$

M. Abdullah Şahin ${ }^{\mathrm{c}}$

M. Levent Demircan ${ }^{\mathrm{d}}$

Abstract: Financial literacy and behavioral biases are critical factors affecting the financial decisions and behaviors of investors. We survey 596 individual stock investors to measure their financial literacy, to examine their behavioral biases and to investigate the relationship between financial literacy and behavioral biases. Results suggest that around half of the investors have a low financial literacy level, their main source of financial information is advice from parents or friends, and they have a high level of behavioral biases. While some of these behavioral biases are independent of the level of financial literacy, there is a significant relationship between a number of other biases and the level of financial literacy.
\end{abstract}

Keywords: Behavioral Finance, Financial Literacy, Behavioral Bias, Financial Decision, Stock Investors

JEL Classification: G02, G11

\section{Introduction}

Financial literacy has been attracting attention at an increasing rate due to factors such as increasing complexity and variety of financial products and services, sophisticated financial decisions that households have to deal with, shifted responsibility for financial security in retirement from government onto individuals and changing economic and demographic factors. This is in line with the findings of a research study conducted by the International Network on Financial Education (INFE) of OECD. The study finds that financial ignorance was one of the factors that exacerbated the impact of the 2007-2009 global financial crisis.

Financial literacy is now globally recognized as an important element of economic and financial stability and development (INFE, 2009). Reflecting this importance, many institutions (e.g. Jump\$tart Coalition for Personal Financial Literacy, National Endowment for Financial Education, Global Financial Literacy Excellence Centre) works on financial literacy at a national or global scale. Much of this work aims to improve individuals' knowledge, with the assumption that increase in knowledge will lead to changes in financial behavior and practice. The validity of this assumption is an issue of interest to the field of

\footnotetext{
${ }^{a}$ Res. Assist., The Institute of Social Sciences, Department of Business Administration, Galatasaray University, Istanbul, Turkiye, sinemats@gmail.com

${ }^{b}$ Assist. Prof. Dr., Department of Management, Faculty of Economics and Administrative Sciences, Boğaziçi University, Istanbul, Turkiye, ali.coskun@boun.edu.tr

'Assist. Prof. Dr., Department of Economics, Faculty of Management, İstanbul Technical University, Istanbul, Turkiye, abdullah.sahin@gmail.com

${ }^{d}$ Assist. Prof. Dr., Department of Industrial Engineering, Faculty of Engineering and Technology, Galatasaray University, Istanbul, Turkiye, leventdemircan@gmail.com
} 
behavioral finance, which aims to shed light on financial behavior by drawing on the disciplines of economics and psychology (Hilgert, Hogarth, and Beverly, 2003: 309).

Statman (1995: 14) defines mainstream finance as a body of knowledge that is built on a number of fundamental principles such as the Miller-Modigliani arbitrage principle, Markowitz's portfolio theory, Linter and Sharpe's capital asset pricing theory and Black-Scholes-Merton option pricing theory. Mainstream finance has shown growth in years based on two fundamental assumptions: "Individuals make rational decisions" and "individuals are without prejudice in forecasting the future." (Nofsinger, 2004: 1). However, behavioral finance, a sub-branch of finance, is based on the assumption that individuals are not fully rational. Thus, behavioral finance is a field that has emerged as an attempt to understand how emotions and cognitive errors affect the decision-making processes of investors (Suer, 2007: 97). Studies conducted in this field has shown that when making financial decisions, individuals may behave irrationally and be under the influence of certain behavioral biases, defined as systematic judgment errors (Kahneman \& Riepe, 1998: 53).

In summary, financial literacy is a key point to be considered when the competence to make wellinformed financial decisions comes into question. However, it is not the only significant determinant of sound financial decision making. Behavioral biases, which affect investor behavior, also play a critical role in this process. People can suffer from behavioral biases and behave irrationally and as a result, can make investment mistakes. On the one hand financial literacy leads to better financial decisions; on the other hand, behavioral biases cause irrational financial behavior.

Although financial literacy is an increasingly important topic in the world as well as in Turkey, academic work based on Turkish data is not abundant. In particular, studies that assess the level of financial literacy and examine its relationship with behavioral biases are scarce. We thus aim to investigate the association between financial literacy and behavioral biases, which may trigger irrationality during the financial decision-making process. This paper contributes to the literature concerning financial literacy level of stock investors and the impact of financial literacy level on the level of behavioral biases.

The main research question addressed in this paper is: "Is there a relationship between a decision maker's financial literacy level and the level of behavioral bias?" In order to answer this question, the relationship between the level of financial literacy and the level of behavioral biases of individual stock investors, whose financial decisions have a material impact not only on their own financial well-being but also on the overall economy, was examined.

The paper is structured as follows: Section 1 gives a review of the literature on financial literacy and behavioral biases. Section 2 presents the methodology, which includes the hypothesis, the data, the variables and the regression model used. Section 3 reports and discusses the results of the analysis. A summary and conclusion part follows.

\section{Literature Review}

A review of the literature on financial literacy and its measurement quickly reveals that there is no common definition for, nor an established method of measuring, financial literacy. Not surprisingly, there are studies that point out this issue and develop definitions and/or measurement methods suggested for widespread use.

President's Advisory Council on Financial Literacy-PACFL (2008:35) defines financial literacy as "the ability to use knowledge and skills to manage financial resources effectively for a lifetime of financial wellbeing". Hung, Parker and Yoong (2009: 11-12) suggest that this definition focuses on the ability to use the knowledge and skills needed to achieve financial welfare and they indicate that it is a behaviorally-based definition. The authors also argue that financial knowledge, skills and behavior, together with the relationships between these concepts, need to be considered to give a comprehensive definition of financial literacy and they offer the following definition: "knowledge of basic economic and financial 
concepts, as well as the ability to use that knowledge and other financial skills to manage financial resources effectively for a lifetime of financial well-being."

Remund (2010: 284), who analyzed more than a hundred resources on financial literacy and confirmed the lack of a common ground for defining and measuring financial literacy, defines financial literacy as "a measure of the degree to which one understands key financial concepts and possesses the ability and confidence to manage personal finances through appropriate, short-term decision-making and sound, long-range financial planning, while mindful of life events and changing economic conditions".

Similarly, the following studies are examples of the great deal of variation in measuring financial literacy. Volpe, Chen and Pavlicko (1996) used 10 multiple choice questions measuring investment knowledge. Hilgert and Beverly (2003) assessed the level of financial literacy using 28 true/false type of financial knowledge questions on topics such as investment, saving, cash flow and so on. In one of their studies, Lusardi and Mitchell used multiple choice questions, 5 of which are basic questions mainly related to the time value of money and 8 of which are advanced questions on more sophisticated issues such as the difference between stock and bond, and the function of the stock market (Lusardi \& Mitchell, 2007b). In another study, they measured financial knowledge using 3 questions on interest rates, inflation and diversification (Lusardi \& Mitchell, 2008).

There are a number of studies on financial literacy in the United States of America (U.S.) and these studies indicate low levels of financial literacy across the U.S. population. Although these studies target the general population (Volpe, Kotel, \& Chen, 2002; Hilgert, Hogarth, \& Beverly, 2003; Lusardi \& Tufano, 2009) or different demographic groups such as university students (Volpe et al., 1996; Chen \& Volpe, 1998) and elderly population (Lusardi \& Mitchell 2007a, 2007b, 2008; Lusardi, Mitchell, \& Curto, 2014), they all find that the level of financial literacy in the U.S. is low. Studies conducted in other countries also report low levels of financial literacy.

Most of the aforementioned studies not only aim to assess financial literacy level, but also to investigate the relationship between financial literacy level and financial behavior. For example; Chen and Volpe (1998) claim that college students' knowledge of personal finance is inadequate and this inadequacy will affect them negatively in their financial decisions. Hilgert et al. (2003) suggest that the success level in the practices such as cash flow management, credit management, saving and investment is higher when the financial literacy level is higher. Lusardi and Mitchell (2007b) find that financial literacy is the primary determinant of retirement planning. Wang's (2009) findings suggest that investors' objective and subjective knowledge and risk taking behaviors are highly correlated. Hibbert, Lawrence and Prakash (2012) conduct a survey to investigate the impact of formal financial education on the management of retirement savings, and find that finance professors are more likely to actively manage their retirement portfolios and less likely to use naive diversification strategies compared to English professors.

The studies on financial literacy in Turkey also suggest low levels of financial literacy (Bayram, 2010; Akyol, 2010; Altıntaş, 2011). Some interesting findings from these studies are as follows: Although their financial literacy level is low, students are not aware of this fact (Bayram, 2010). Financial awareness of private banking employees still needs to be enhanced in spite of their advantages such as higher education, and professional experience (Akyol, 2010). Educational background of students (business majors/nonbusiness majors) does not have a significant impact on their financial literacy level (Altıntaş, 2011).

Although not studying behavioral finance in a technical sense, the following papers look into the relationship between financial literacy and various aspects of financial behavior: Bayram (2010) analyzes the financial literacy level and money management behavior of university students and finds that students perceive the term "financial literacy" in a narrow sense as "saving money regularly, paying the bill on time, keeping the financial records", and their main source of knowledge about money management and spending is their families. Araz (2012) conducts an analysis in two parts to analyze the effect of financial literacy on credit card arrears. In the first model, financial literacy, income and wealth are found to have no effect. However, in the second model, she finds that people hit by external shocks can overcome financial difficulties and avoid defaults if they are financially literate and if they have a high income and a big 
Impact of Financial Literacy on the Behavioral Biases of Individual Stock Investors: Evidence from Borsa Istanbul

household population. Sevim, Temizel and Sayllır (2012) conduct a survey in order to measure the effect of financial literacy of Turkish financial consumers on their borrowing behavior. Their results indicate that financial consumers with a higher level of financial literacy are not expected to exhibit excessive borrowing behavior and more likely to use their credit cards in an informed manner.

Sezer and Demir (2015) examine the relationship between the financial literacy and behavioral biases of Turkish investors. They find that there is no correlation between investors' behavioral biases and their financial literacy level. To the best of our knowledge, this is the only academic work that uses Turkish data to look into the relationship between the financial literacy and behavioral biases.

Because financial literacy studies do not have a common method of measurement, financial literacy levels found in these studies are not comparable. However, The OECD/International Network on Financial Education (INFE) developed a questionnaire aimed to have a comprehensive measurement of financial literacy of individuals with different backgrounds in different countries. INFE conducted this questionnaire in 14 countries throughout 4 continents (Atkinson \& Messy, 2012). Berberoğlu, Çoşkun and Şahin (2014) carried out the OECD/INFE survey in Turkey and obtained Turkish data that is comparable to the data of other countries in the INFE survey. They find that a financial literacy index for Turkey is 59.8 while the same index value for other countries is 62.3 (The Economy Bank of Turkey, 2014).

As mentioned before, it is crucial to analyze behavioral biases as well as financial literacy in order to understand actual investor behavior. It was shown by many studies that both financial literacy and behavioral biases affect investor behavior. However, the relationship between these two concepts, which has a crucial role in investors' financial decisions and behavior, has not been investigated in depth. There are several academic works that suggest individuals with a low level of financial knowledge and cognitive ability are more likely to suffer from biases and make investment mistakes (Bucher-Koenen \& Ziegelmeyer, 2011). More specifically; low levels of financial literacy were found to be correlated with the lack of portfolio diversification (Guiso \& Japbelli, 2008; Abreu \& Mendes, 2010; Kimball \& Shumway, 2010), home bias (Kimball \& Shumway, 2010) and peer effects (Duflo \& Saez, 2003; Benartzi \& Thaler, 2007). This is how we contribute to the literature; namely, by looking into the relationship between the financial literacy and behavioral biases. Traditional finance theories such as expected utility theory, and efficient market hypothesis are not concerned with the actual investor behavior and its consequences; they assume the investor is "rational" and discuss how the rational investor should behave. On the contrary, investors are not rational, but normal, in behavioral finance. How the investors behave in reality and the market anomalies that arise from this behavior are the issues behavioral finance addresses. Therefore, behavioral finance is defined in the literature as: "the application of psychology to financial behavior" (Shefrin, 2002: $3)$, "it argues that some financial phenomena can be better understood using models in which some agents are not fully rational" (Barberis \& Thaler, 2003: 1053).

Behavioral biases that prevent investors from being rational, termed "systematic errors of judgment" (Kahneman \& Riepe, 1998: 53), are important tools of behavioral finance to explain the irrational behavior of investors. For instance, conservatism, defined as "tendency to cling tenaciously to a view or a forecast" (Montier, 2002: 4), causes investors to underreact to new information; overoptimism, defined as "overestimate of the probability that a favorable outcome will occur, or underestimate that a negative outcome will occur" (Puri \& Robinson, 2007: 8) causes one to focus on the more promising events while analyzing financial reports or analyst forecasts. Because determination and classification of behavioral biases that have an impact on investor behavior is quite complex and difficult, there are different lists and classifications for behavioral biases in the literature. In explaining behavioral biases, this study is based on the classification of Montier (2007), who simplified Hirshleifer's (2001) complex classification in order to outline the most common biases and to emphasize the ones that have direct possible outcomes in terms of investment. 


\section{Methodology}

\subsection{Data}

To collect the necessary data, we conducted a survey using a questionnaire composed of three parts:

The first part of the questionnaire aims to elicit information about the investor's stock investment experience, financial information sources used by the investor and a self-assessment of the investor's level of financial literacy, together with some basic demographics.

The second part aims to measure the level of financial literacy. To this end, a 20-item financial knowledge scale developed by Knoll and Houts (2012) and the 10-item financial sophistication scale of Lusardi et al. (2014) are used after the necessary modifications to fit them in the Turkish context. The first scale contains multiple choice questions on topics such as interest (1 question), inflation (1 question), time value of money (1 question), investment (7 questions), risk diversification (2 questions), housing (2 questions), debt management (1 question), retirement savings (2 questions), life insurance (2 questions) and annuities (1 question). Financial sophistication scale covers the topics of the knowledge of capital markets ( 3 questions), risk diversification ( 2 questions), the knowledge of fees ( 2 questions), and savvy/numeracy (3 questions). We select the scale of Knoll and Houts (2012) as the baseline for this study since it contains questions on a wide variety of topics.

The last part contains 30 questions aimed at detecting behavioral biases. We draw on the relevant literature to compose this set of questions. We record the responses on a five-point Likert type scale.

We also conduct a reliability analysis; the financial literacy scale has a high degree of internal consistency, with a Cronbach's alpha of 0.824 and the behavioral bias scale is quite reliable, with a Cronbach's alpha of 0.782 .

\subsection{Sample}

According to the data from the Central Registry Agency of Turkey, the number of stock investors in Turkey is 1.081 .909 as of June, 2014 . $99 \%$ of this $(1,072,624)$ are individual stock investors and $99 \%$ of individual stock investors $(1,066,733)$ are Turkish nationals. $31 \%$ of the Turkish individual stock investors live in Istanbul. Moreover, the total portfolio value of individual stock investors living in Istanbul (25.170 million TRY) constitutes $61 \%$ of the total portfolio value of individual stock investors in Turkey (41.376 million TRY). Hence, assuming Istanbul is home to a representative subset of the individual stock investors in Turkey, and in an effort to contain the costs within our budget, we conducted the questionnaire with 605 individual stock investors selected by random sampling from Istanbul. 9 out of 605 questionnaires were excluded from the analysis due to missing data, so the analysis was done with 596 questionnaires.

\subsection{Variables and Measurement}

\subsubsection{Dependent Variable}

Level of behavioral biases: Respondents are presented with a list of 30 statements that exemplify 15 behavioral biases ( 2 statements for each behavioral bias) and the responses are taken on a five-point Likert scale, ranging from " $1=$ strongly disagree" to " $5=$ strongly agree". The average of an investor's responses to the 2 statements representing the same bias is taken to be the level of the relevant behavioral bias. Finally, each of the behavioral biases (representativeness, confirmation, hindsight, self-attribution, anchoring, conservatism, overoptimism, availability, categorization, cognitive dissonance, framing, illusion of knowledge, illusion of control, loss aversion, and overconfidence) is used as the dependent variable in the regression model described below. 


\subsubsection{Independent Variables}

Financial literacy: The financial literacy score of each respondent is calculated by assigning 1 point to each correct response and then adding up the points earned. The sample mean is 11.8 and the median is 12. Respondents with a financial literacy score higher than 12 are classified as investors with a high level of financial literacy and respondents with a score less than 12 as investors with a low level of financial literacy.

\subsubsection{Control Variables}

There are numerous studies finding that demographic factors have an impact on some behavioral biases (e.g., Barber \& Odean, 2001; Bhandari \& Deaves, 2006; Baddeley et al. 2010; Lin, 2011; Jamshidinavid, Chavoshani \& Amiri, 2012). Accordingly, we add gender, marital status, age, education, investment experience, source of financial information and investors' self-assessed literacy levels as control variables in our regression models to isolate the direct impact of financial literacy on behavioral biases.

Gender: male or female

Marital status: married or single

Age: Respondents between the ages of 18 and 60 are working-age investors and those over the age of 60 are retirement-age investors.

Education: Primary school, high school and college graduates are grouped as non-university graduates and those with a bachelor's or graduate degree are grouped as university graduates.

Investment experience: Respondents with an investment experience of 1 year or less are classified as inexperienced whereas those with an investment experience of more than 1 year are classified as experienced.

Source of financial information: Respondents who ask for advice from parents or friends when making investment decisions ( $40.3 \%$ of the sample) form the group of advice from parents or friends and respondents who use other financial information sources (periodicals, media, internet etc.) form the group of other information sources.

Self-assessed literacy level: low level, medium level or high level.

\subsection{The Regression Model and Hypothesis}

To determine the impact of the level of financial literacy on the level of behavioral biases, ordinal regression models are built for each of the behavioral biases. The regression model and the variables in the model are as follows:

$$
\begin{aligned}
y(\text { BiasLevel }) & =b_{0}+b_{1}(\text { FLiteracy })+b_{2}(\text { Gender })+b_{3}(\text { MaritalStatus })+b_{4}(\text { Age })+b_{5}(\text { Education }) \\
& +b_{6}(\text { InvestmentExp. })+b_{7}(\text { InfoSource })+b_{8}(\text { SelfAssessedLiteracy } 1) \\
& +b_{9}(\text { SelfAssessedLiteracy } 2)+e_{i}
\end{aligned}
$$

where: BiasLevel - 1 if the level of behavioral bias is up to 3, 2 if it equals 3, 3 otherwise; FLiteracy1 if the financial literacy level of a respondent is high, 0 otherwise; Gender -1 if a respondent is a male, 0 otherwise; MaritalStatus - 1 if a respondent is married, 0 otherwise; Age - 1 if a respondent is in retirement age, 0 otherwise; Education - 1 if a respondent is a university graduate, 0 otherwise; InvestmentExp. -1 if a respondent is experienced, 0 otherwise; InfoSource - 1 if a respondent's main source of financial information is advice from parents or friends, 0 otherwise; SelfAssessedLiteracy $1-1$ if a respondent's self-assessment of his/her financial literacy level is medium level, 0 otherwise; SelfAssessedLiteracy2 - 1 if a respondent's self-assessment of his/her financial literacy level is high level, 0 otherwise.

Multicollinearity is a common issue in empirical studies. So we also checked for the extent of multicollinearity between independent variables in the model. "Collinearity diagnostics" can be obtained 
while running a linear regression in SPSS. We run a linear regression for the model above and check the "variance inflation factor (VIF)" scores. All the VIF values obtained are between 1 and 2. This means multicollinearity does not exist between the independent variables in the model.

Based on the literature which indicates a negative relationship between the level of financial knowledge/cognitive ability and the possibility to suffer from behavioral biases, the main research hypothesis of this study can be stated as: A low level of financial literacy increases the likelihood of the investor being affected by behavioral biases. We have sub-hypotheses and run our regression model for each of the behavioral biases which we measured by the questions in our survey.

\section{Analysis and Results}

\subsection{Demographic Variables}

According to demographic characteristics, the sample is mostly composed of males (78.2\%) and the majority (72\%) is between $20-39$ years old. $41.3 \%$ have a bachelor's degree and $37.9 \%$ are high school graduates. $56.2 \%$ are married and $43.8 \%$ are single investors. $67 \%$ have less than 4 years of stock investment experience. Asked about their main source of financial information, $40.3 \%$ indicate advice from parents or friends as the most commonly used source of information. When asked to assess their financial knowledge level by selecting one of the choices from "low level", "medium level" and "high level", 18.3\% assess their financial knowledge level as "low", 66.9\% as "medium" and $14.8 \%$ as "high". Table 1 in the appendix shows the summary of demographic characteristics of the sample.

\subsection{Analysis of Financial Literacy}

We first split our sample into two groups based on the financial literacy scores of the respondents; $56.54 \%$ of the sample has a score that is higher than or equal to the sample median, 12 , and $43.46 \%$ has a score that is lower than the sample median.

Interestingly, a majority of the respondents do not know the difference between the investment instruments such as stocks, bonds, mutual funds in terms of risk and return characteristics. Likewise, more than half do not know that it is not possible to eliminate credit card debt by paying only the minimum amount due and default interest. Similarly, a majority of them do not know for how long they need to stay in the private pension system and the minimum age to be able to retire.

We conduct ANOVA/t-tests to compare the investors' level of financial literacy based on demographic variables. Education level, investment experience and sources of financial information do not make any difference in terms of financial literacy level. On the other hand; we find significant differences in the level of financial literacy across gender, marital status, age and investors' self-assessed literacy. In particular, women versus men, married ones versus single ones and the respondents in retirement age (over the age of 60 ) versus those in working age (between the age of 18 and 60 ) have a significantly higher level of financial literacy. Also, post hoc analysis shows that investors who assess their financial literacy level as "high" indeed have significantly higher levels of financial literacy compared to those who assess themselves as having a "low" level of financial literacy. Table 2 in the appendix shows the ANOVA/t-tests statistics regarding the financial literacy level based on demographics.

\subsection{Analysis of Behavioral Biases}

The average of an investor's responses to the 2 statements representing the same bias is taken to be the level of the relevant behavioral bias. The sample mean is over 3.25 for each of the biases. This suggests that the respondents have a high level of the behavioral biases investigated in this study. The representativeness, confirmation, and hindsight biases have the highest sample averages, 3.79, 3.70, and 3.64 , respectively. Table 3 in the appendix shows the mean values of the behavioral biases.

We conduct ANOVA/t-tests to compare the levels of behavioral biases across different subsamples. We find that: 
- Illusion of control, illusion of knowledge, overconfidence, hindsight and framing biases are greater for males than for females.

- Single investors' level of overoptimism, illusion of knowledge, overconfidence and loss aversion biases is significantly higher than the married investors. On the contrary, cognitive dissonance is significantly higher for married investors.

- Working-age investors have a significantly higher level of loss aversion bias than retirementage investors do.

- Investors without an undergraduate degree have significantly higher levels of representativeness and categorization biases.

- Investors who have investment experience of more than 1 year are significantly more likely to suffer from overconfidence, self-attribution, hindsight, cognitive dissonance, conservatism, framing and anchoring biases compared to investors who have investment experience of 1 year or less.

- Investors that cite advice from parents or friends as their main source of financial information are more prone to availability bias compared to investors who use other sources of financial information.

- There are significant differences in the levels of illusion of control, overconfidence and selfattribution biases across different subsamples of self-assessed financial literacy.

Table 4 in the appendix shows the ANOVA/t-tests results statistics regarding the level of behavioral biases based on demographics.

\subsection{Relationship Between Financial Literacy and Behavioral Bias}

Lastly, we run ordinal regression models with each of the behavioral biases as the dependent variables. We find a positive significant relationship between the level of financial literacy and the level of overoptimism, confirmation and representativeness, and a significant negative relationship between the level of financial literacy and the level of overconfidence, cognitive dissonance, framing and loss aversion biases. In other words, our results suggest that when the level of financial literacy increases, the levels of overoptimism, confirmation and representativeness increase and the levels of overconfidence, cognitive dissonance, framing and loss aversion biases decrease significantly. The results of the regressions with a significant chi-square statistic (at $1 \%$ or $5 \%$ level) for model fitting are presented in the Appendix.

This mixed result regarding the relationship between financial literacy and behavioral biases may be due to various factors. As Collins and O'Rourke (2010: 483) state: "Consumers face more than informational barriers when they make financial decisions. For instance, consumers may lack self-control or exhibit other behavioral biases that education and counseling may not enable them to overcome. "So, it is possible that education and accordingly financial literacy may not be enough to eliminate some behavioral biases. On the other hand, lack of financial knowledge may not cause a problematic situation if the consumer learns through trial and error (Campbell et.al. 2011).

\section{Conclusions}

Our main objective in this study is to investigate the relationship between the financial literacy level of investors and the level of behavioral biases that may result in irrational behavior in financial decisionmaking. We also examine the demographic factors that influence the level of financial literacy and behavioral biases.

To this end, we analyze a random sample of 596 individual stock investors in Istanbul, Turkey. Advice from parents or friends is found to be the most preferred source of financial information (40.3\%). This finding contradicts with the finding of Sezer and Demir (2015), who find that advice from friends are 
the least preferred source of financial information for the investors. Internet (22.3\%) and investors' own analysis (13.4\%) are also among the most commonly used information sources. At the other end are financial reports of the companies (2.2\%), reports and analysis of stock brokers (3.5\%) and media (3.5\%).

Female, married and retirement-age investors have a higher level of financial literacy than male, single and working-age investors, respectively. The literature on the financial literacy of investors' reports mixed results regarding the impact of demographic factors on the level of financial literacy. Abreu and Mendes (2010) and Al-Tamimi and Bin Kalli (2009) find that females have a lower level of financial literacy than males, while Sezer and Demir (2015) conclude that gender has no impact on the level of financial literacy. Abreu and Mendes (2010) and Sezer and Demir (2015) find age to be a significant determinant of financial literacy whereas Al-Tamimi and Bin Kalli (2009) suggest otherwise. Education has a positive effect on the level of financial literacy in all of these studies. Unlike our study, Abreu and Mendes (2010) suggest that married investors' level of financial literacy is lower. As for self-assessment, we find that $62.5 \%, 57.9 \%$, and $46.8 \%$ of the investors who assess their financial literacy level as "high", "medium", and "low", respectively, indeed have a high level of financial literacy. This suggests that investors are quite aware of their level of financial literacy.

Although the investors have a high level of all the behavioral biases mentioned in this study; representativeness, confirmation and hindsight biases are the most common biases among investors. More precisely, because of representativeness bias, investors believe that the stocks of well-known companies are good stocks and past performance of the companies is representative of their future performance, but they fail to notice the fact that good companies do not perform well and bad companies do not perform poorly at all times (Nofsinger, 2004). Confirmation bias causes investors to pay attention to views that approve their investment decisions and to ignore views that conflict with them instead of questioning their investment decisions objectively. Investors with hindsight bias believe that they had predicted the results of the past events before they happened, even though the events were unexpected economic events such as a financial or economic crisis, or sudden changes in the exchange rates (Pompian, 2011).

One of the most notable results regarding the behavioral biases is males' higher level of illusion of control, illusion of knowledge, overconfidence, hindsight and framing biases compared to females. Sezer and Demir (2015) also find that males have higher level of overreaction bias, familiarity bias, home bias and disposition effect. These findings are consistent with males being more prone to biases and hence more likely to make investment mistakes. Another noteworthy finding is that experienced investors (who have stock investment experience of more than 1 year) are more likely to suffer from overconfidence, selfattribution, hindsight, cognitive dissonance, conservatism, framing and anchoring biases compared to inexperienced investors. This suggests that market experience does not lower the level of behavioral biases. Finally, we find that investors who assess their level of financial literacy as "high" have higher levels of overconfidence and illusion of control biases.

Contrary to our expectations, there is not a standing and one-way relationship between the level of financial literacy and the level of behavioral biases. We find a significant relationship between the level of financial literacy and the level of bias for 7 out of 15 behavioral biases examined in this paper. This relationship is positive for the overoptimism, confirmation and representativeness and negative for overconfidence, cognitive dissonance, framing and loss aversion. These mixed results may be due to some undiscovered factor that has an impact on the level of behavioral biases. This point should be addressed in future research.

Related to this point, there are similar terms in the literature such as financial awareness, financial capability, financial competence, financial education, financial knowledge and financial literacy (Miller et.al. 2014). Although they seem to be synonyms at first glance, they have different meanings. We focus on financial literacy in our study in order to find its effect on behavioral biases. However, financial literacy may not be the exact measure that has the principal effect on behavioral biases. Besides, financial literacy has different components in itself such as financial knowledge, financial skills, financial behaviors and financial attitudes. The financial literacy scale used in this study contains questions assessing only financial 
knowledge component of financial literacy (Knoll and Houts, 2012). This may also be an explanation for our mixed result.

One policy-related suggestion of our results stands out: Efforts to increase financial literacy level of the investors will not eliminate all the behavioral biases. To ensure well-informed financial decisions, spreading awareness of behavioral biases is also necessary. Financial education programs should be designed accordingly.

In future research, aspects of financial literacy other than financial knowledge can also be included in the scales as an attempt to fully uncover the relationship between financial literacy and behavioral biases. In addition, whichever measure or scale is used an empirical study, the academic community should try to come up with a common measure so that studies across countries and time can be reliably compared.

\section{End Notes}

*We thank Bogazici University for providing us with the financial support (Bogazici University Research Fund; project code: 6742) to run the questionnaire that forms the basis of this study.

\section{References}

Abreu, M., \& Mendes, V. (2010). Financial literacy and portfolio diversification. Quantitative Finance, 10(5): 515-528.

Akyol, C. (2010). Effects of financial awareness on investor choice: A research concerning financial awareness of private bank workers. Master's thesis, Anadolu University Institute of Social Sciences, Eskişehir.

Altıntaş, K. M. (2011). The dynamics of financial literacy within the framework of personal finance: An analysis among Turkish university students. African Journal of Business Management, 5(26): 10483-10491.

Araz, T. (2012). Financial literacy and credit card arrears. Master's thesis, Boğaziçi University Institute of Social Sciences, ìstanbul.

Atkinson, A., \& Messy, F. (2012). Measuring Financial Literacy: Results of the OECD / International Network on Financial Education (INFE) Pilot Study. OECD Working Papers on Finance, Insurance and Private Pensions, No. 15, OECD Publishing.

Baddeley, M., Burke, C., Schultz, W., \& Tobler, P. (2010). Impacts of personality on herding in financial decisionmaking. University of Cambridge, Faculty of Economics.

Barber, B. M., \& Odean, T. (2001). Boys will be boys: Gender, overconfidence, and common stock investment. Quarterly Journal of Economics, 261-292.

Barberis, N., \& Thaler, R. (2003). A survey of behavioral finance. Chapter 18 in Constantinides, G.M., Harris, M., Stulz, R. (Eds.), Handbook of the Economics of Finance (pp. 1052-1121). Elsevier Science B.V.

Bayram, S.S. (2010). Financial literacy and money management behaviours: Application on students of Anadolu University. Master's thesis, Anadolu University Institute of Social Sciences, Eskişehir.

Benartzi, S., \&Thaler, R. H. (2007). Heuristics and biases in retirement savings behavior. Journal of Economic Perspectives, 21(3): 81-104.

Berberoğlu, M. G., Çoşkun, A., \& Şahin, M. A. (2014). Financial literacy in Turkey: A field study to touch base with the OECD, Boğaziçi University Working Paper.

Bhandari, G., \& Deaves, R. (2006). The demographics of overconfidence. The Journal of Behavioral Finance, 7(1): 5-11.

Bucher-Koenen, T., \& Ziegelmeyer, M. (2011). Who lost the most? Financial literacy, cognitive abilities and the financial crisis, ECB Working Paper Series, 1299.

Campbell, J. Y., Jackson, H. E., Madrian, B. C., \& Tufano, P. (2011). Consumer financial protection. The Journal of Economic Perspectives: A Journal of The American Economic Association, 25(1): 91.

Chen, H., \& Volpe, R. P. (1998). An analysis of personal financial literacy among college students. Financial Services Review, 7(2): 107-128. 
Collins, J. M., \& O'rourke, C. M. (2010). Financial education and counseling-Still holding promise. Journal of Consumer Affairs, 44(3): 483-498.

Duflo, E., \& Saez, E. (2003). The role of information and social interactions in retirement plan decisions: Evidence from a randomized experiment. Quarterly Journal of Economics, 118(3): 815-842.

Guiso, L., \& Jappelli, T. (2008). Financial literacy and portfolio diversification. EUI Working Paper, 31.

Hibbert, A. M., Lawrence, E. R., \& Prakash, A. J. (2012). The role of financial education in the management of retirement savings. Journal of Behavioral Finance, 13(4): 299-307.

Hilgert, M. A., Hogarth, J. M., \& Beverly, S. G. (2003). Household financial management: The connection between knowledge and behavior. Federal Reserve Bulletin, 89: 309-322.

Hirshleifer, D. (2001). Investor psychology and asset pricing. The Journal of Finance, 56(4): 1533-1597.

Hung, A. A., Parker, A. M. \& Yoong J. K. (2009). Defining and measuring financial literacy. RAND Working Paper Series, No.708.

INFE. (2009). Financial education and the crisis: Policy paper and the guidance. (http://www.oecd.org/finance/financial-education/50264221.pdf).

Jamshidinavid, B., Chavoshani, C., \& Amiri, S. (2012). The Impact of Demographic and Psychological Characteristics on the Investment Prejudices in Tehran Stock. European Journal of Business and Social Sciences, 1(5): 41-53.

Kahneman, D., \& Riepe, M. W. (1998). Aspects of investor psychology. The Journal of Portfolio Management, 24(4): 52-65.

Kimball, M. S., \& Shumway, T. (2010). Investor sophistication and the home bias, diversification and employer stock puzzles. University of Michigan Working Paper.

Knoll, M. A., \& Houts, C. R. (2012). The financial knowledge scale: An application of item response theory to the assessment of financial literacy. Journal of Consumer Affairs, 46(3): 381-410.

Lin, H. W. (2011). Elucidating the influence of demographics and psychological traits on investment biases. World Academy of Science, Engineering and Technology, 77: 145-150.

Lusardi, A., \& Mitchell, O. S. (2007a). Baby boomer retirement security: The roles of planning, financial literacy and housing wealth. Journal of Monetary Economics, 54(1): 205-224.

Lusardi, A., \& Mitchell, O. S. (2007b). Financial literacy and retirement planning: New evidence from the Rand American Life Panel. CFS Working Paper, No. 2007/15.

Lusardi, A., \& Mitchell, O. S. (2008). Planning and financial literacy: How do women fare?. American Economic Review: Papers \& Proceedings, 98(2): 413-417.

Lusardi, A., \& Tufano, P. (2009). Debt literacy, financial experiences and overindebtedness. NBER Working Paper Series, No. 14808.

Lusardi, A., Mitchell, O. S., \& Curto, V. (2014). Financial literacy and financial sophistication in the older population. Journal of Pension Economics and Finance, 1-20.

Miller, M., Reichelstein, J., Salas, C., \& Zia, B. (2014). Can you help someone become financially capable? a metaanalysis of the literature. A Meta-Analysis of the Literature. World Bank Policy Research Working Paper, (6745).

Montier, J. (2002). Behavioural finance: Insights into irrational minds and markets. New Jersey: John Wiley \& Sons.

Montier, J. (2007). Behavioral investing: A practitioner's guide to applying behavioral finance. New Jersey: John Wiley \& Sons.

Nofsinger, J. R. (2004). The psychology of investing. Upper Saddle River, New Jersey: Prentice Hall.

Pompian, M. (2011). Behavioral finance and wealth management: How to build optimal portfolios that account for investor biases. New Jersey: John Wiley \& Sons.

President's Advisory Council on Financial Literacy (PACFL). (2008). 2008 Annual Report to the President.http://www.treasury.gov/resource-center/financial education/Documents/PACFL_ANNUAL_REPORT_1-16-09.pdf (Access date 06.09.2013).

Puri, M., \& Robinson, D. T. (2007). Optimism and economic choice. Journal of Financial Economics, 86(1): 71-99.

Remund, D. L. (2010). Financial literacy explicated: The case for a clearer definition in an increasingly complex economy. The Journal of Consumer Affairs, 44(2): 276-295.

Sevim, N., Temizel, F. ve Sayılır, Ö. (2012). The effects of financial literacy on the borrowing behaviour of Turkish financial consumers. International Journal of Consumer Studies, 36(5): 573-579. 
Sezer, D., \& Demir, S. (2015). Investors' levels of financial literacy and cognitive ability and their relationship with psychological illusions. Journal of Accounting \& Finance, April.

Shefrin, H. (2002). Beyond greed and fear: Understanding behavioral finance and the psychology of investing. New York: Oxford University Press.

Statman, M. (1995). Behavioral finance versus standard finance. In A.S.Wood (Eds.), Behavioral Finance and Decision Theory in Investment Management (14-22). Charlottesville, VA: Association for Investment Management and Research.

Süer, Ö. (2007). An empirical study about the determination of risk behaviour in investment decisions. Öneri, 7(28): 97-105.

The Economoy Bank of Turkey, (2014). Financial Literacy and Access Index. Retrieved July 2 2014, from http://www.teb.com.tr/document/finansal-okuryazarlik-ve-erisim-endeksi.pdf

Volpe, R. P., Chen, H., \& Pavlicko, J. J. (1996). Personal investment literacy among college students: A survey. Financial Practice and Education, 6(2): 86-94.

Volpe, R. P., Kotel, J. E., \& Chen, H. (2002). A survey of investment literacy among online investors. Financial Counseling and Planning, 13(1): 1-13.

Wang, A. (2009). Interplay of investors' financial knowledge and risk taking. Journal of Behavioral Finance, 10(4): 204213. 


\section{Appendix}

Table 1. Demographics of the Sample

\begin{tabular}{|c|c|c|}
\hline$(N=596)$ & $\begin{array}{l}\text { Number of } \\
\text { respondents }\end{array}$ & $\begin{array}{l}\text { Percentage } \\
\text { (\%) }\end{array}$ \\
\hline \multicolumn{3}{|l|}{ Gender } \\
\hline Male & 466 & 78.2 \\
\hline Female & 130 & 21.8 \\
\hline \multicolumn{3}{|l|}{ Marital status } \\
\hline Married & 335 & 56.2 \\
\hline Single & 261 & 43.8 \\
\hline \multicolumn{3}{|l|}{ Age } \\
\hline 0-19 & 8 & 1.3 \\
\hline $20-29$ & 209 & 35.1 \\
\hline $30-39$ & 220 & 36.9 \\
\hline $40-49$ & 91 & 15.3 \\
\hline $50-59$ & 48 & 8.1 \\
\hline 60 and over & $\begin{array}{l}48 \\
20\end{array}$ & 34 \\
\hline \multicolumn{3}{|l|}{ Education } \\
\hline Primary school & & \\
\hline High school & 64 & 10.7 \\
\hline Two-year degree & 226 & 37.9 \\
\hline Bachelor's degree & 46 & 7.7 \\
\hline Postgraduate degree & 246 & 41.3 \\
\hline \multicolumn{3}{|l|}{$\begin{array}{l}\text { Postgraduate degree } \\
\text { Stock investment experience }\end{array}$} \\
\hline Less than 1 year & & \\
\hline $1-3$ years & 227 & 38.1 \\
\hline $4-6$ years & 172 & 28.9 \\
\hline $7-9$ years & 84 & 14.1 \\
\hline More than 10 years & 37 & 6.2 \\
\hline \multirow{2}{*}{\multicolumn{3}{|c|}{$\begin{array}{l}\text { Source of financial information } \\
\text { Advice from parents or friends }\end{array}$}} \\
\hline & & \\
\hline Periodicals & 240 & 40.3 \\
\hline Media & 31 & 5.2 \\
\hline Internet & 21 & 3.5 \\
\hline Advice from professional investment & 133 & 22.3 \\
\hline advisors & 57 & 9.6 \\
\hline Reports and analysis of stock brokers & 21 & 3.5 \\
\hline Financial reports of the companies & 13 & 2.2 \\
\hline Own analysis & 80 & 13.4 \\
\hline \multicolumn{3}{|l|}{ Self assessed literacy } \\
\hline Low level & 109 & 18.3 \\
\hline Medium level & 399 & 66.9 \\
\hline High level & 88 & 14.8 \\
\hline
\end{tabular}


Table 2. Financial Literacy Based on Demographics

\begin{tabular}{|c|c|c|c|c|c|}
\hline & \multicolumn{2}{|c|}{$\begin{array}{c}\text { Financial literacy } \\
\text { level }\end{array}$} & \multirow[b]{2}{*}{$t / F$} & \multirow[b]{2}{*}{$p$} \\
\hline & & Low (\%) & High (\%) & & \\
\hline \multirow{2}{*}{ Gender } & Male & 45.3 & 54.7 & \multirow{2}{*}{-1.728} & \multirow{2}{*}{$0.085^{*}$} \\
\hline & Female & 36.9 & 63.1 & & \\
\hline \multirow{2}{*}{ Marital status } & Married & 39.7 & 60.3 & \multirow{2}{*}{2.094} & \multirow{2}{*}{$0.037 * *$} \\
\hline & Single & 48.3 & 51.7 & & \\
\hline \multirow[t]{2}{*}{ Age } & $\begin{array}{l}\text { Retirement age (over } \\
60 \text { ) }\end{array}$ & 44.1 & 55.9 & \multirow[t]{2}{*}{2.210} & \multirow[t]{2}{*}{$0.043 * *$} \\
\hline & Working age (18-60) & 20.0 & 80.0 & & \\
\hline \multirow[b]{2}{*}{ Education } & University graduates & 45.5 & 54.5 & \multirow[b]{2}{*}{1.165} & \multirow[b]{2}{*}{0.244} \\
\hline & $\begin{array}{l}\text { Non-university } \\
\text { graduates }\end{array}$ & 40.8 & 59.2 & & \\
\hline \multirow{2}{*}{$\begin{array}{l}\text { Stock investment } \\
\text { experience }\end{array}$} & Experienced & 41.4 & 58.6 & \multirow[t]{2}{*}{-1.067} & \multirow[t]{2}{*}{0.287} \\
\hline & Inexperienced & 45.7 & 54.3 & & \\
\hline \multirow{2}{*}{$\begin{array}{l}\text { Source of } \\
\text { financial info. }\end{array}$} & $\begin{array}{c}\text { Advice from parents or } \\
\text { friends }\end{array}$ & 46.2 & 53.8 & \multirow{2}{*}{-1.126} & \multirow{2}{*}{0.261} \\
\hline & Others & 41.6 & 58.4 & & \\
\hline \multirow{3}{*}{$\begin{array}{l}\text { Self-assessed } \\
\text { financial literacy }\end{array}$} & Low level & 53.2 & 46.8 & \multirow{3}{*}{2.913} & \multirow{3}{*}{$0.056^{*}$} \\
\hline & Medium level & 42.1 & 57.9 & & \\
\hline & High level & 37.5 & 62.5 & & \\
\hline
\end{tabular}

Note: Significant at the ${ }^{* * *} 1 \%, * * 5 \%, * 10 \%$ level.

Table 3. Level of Investors' Behavioral Biases

\begin{tabular}{c|c}
\hline Behavioral bias & Mean value \\
\hline Representativeness & 3.79 \\
\hline Confirmation & 3.70 \\
\hline Hindsight & 3.64 \\
\hline Self attribution & 3.61 \\
\hline Anchoring & 3.60 \\
\hline Conservatism & 3.59 \\
\hline Over optimism & 3.57 \\
\hline Availability/Salience/Cue & 3.48 \\
\hline competition & 3.47 \\
\hline Categorization & 3.40 \\
\hline Cognitive dissonance & 3.39 \\
\hline Framing & 3.38 \\
\hline Illusion of knowledge & 3.35 \\
\hline Illusion of control & 3.35 \\
\hline Loss aversion & 3.26 \\
\hline Overconfidence &
\end{tabular}


S. Ates - A. Coskun - M. A. Sahin - M. L. Demircan

Table 4. Behavioral Biases Based on Demographics

\begin{tabular}{|c|c|c|c|}
\hline Variable & Behavioral bias & $t / F$ & $p$ \\
\hline \multirow{5}{*}{ Gender } & Illusion of control & 4.170 & $0.000 * * *$ \\
\hline & Illusion of knowledge & 2.089 & $0.038 * *$ \\
\hline & Overconfidence & 2.955 & $0.003 * * *$ \\
\hline & Hindsight & 3.828 & $0.000 * * *$ \\
\hline & Framing & 3.169 & $0.002 * * *$ \\
\hline \multirow{5}{*}{ Marital status } & \begin{tabular}{|l} 
Overoptimism \\
\end{tabular} & -2.311 & $0.021^{* *}$ \\
\hline & Illusion of knowledge & -1.965 & $0.050 * *$ \\
\hline & \begin{tabular}{|l|} 
Overconfidence \\
\end{tabular} & -2.734 & $0.006 * * *$ \\
\hline & Cognitive dissonance & 2.876 & $0.004 * * *$ \\
\hline & Loss aversion & -2.424 & $0.016 * *$ \\
\hline Age & Loss aversion & -3.408 & $0.001 * * *$ \\
\hline \multirow{2}{*}{ Education } & Representativeness & -2.089 & $0.037^{* *}$ \\
\hline & Categorization & -3.227 & $0.001 * * *$ \\
\hline \multirow{7}{*}{ Investment experience } & Overconfidence & 2.958 & $0.003^{* * *}$ \\
\hline & Self attribution & 2.026 & $0.043^{* *}$ \\
\hline & \begin{tabular}{|l} 
Hindsight \\
\end{tabular} & 2.501 & $0.013^{* *}$ \\
\hline & Cognitive dissonance & 2.984 & $0.003^{* * *}$ \\
\hline & \begin{tabular}{|l} 
Conservatism \\
\end{tabular} & 3.915 & $0.000 * * *$ \\
\hline & Framing & 2.157 & $0.031^{* *}$ \\
\hline & Anchoring & 2.199 & $0.028 * *$ \\
\hline $\begin{array}{c}\text { Source of financial } \\
\text { info. }\end{array}$ & Availability & 2.298 & $0.022 * *$ \\
\hline \multirow{3}{*}{ Self-assessed literacy } & Illusion of control & 2.886 & $0.057^{*}$ \\
\hline & Overconfidence & 18.160 & $0.000 * * *$ \\
\hline & Self attribution & 2.736 & $0.066^{*}$ \\
\hline
\end{tabular}

Note: Significant at the $* * * 1 \%, * * 5 \%, * 10 \%$ level.

Table A1: Ordinal Regression Results for Overoptimism

\begin{tabular}{|c|c|c|c|c|c|}
\hline & $\begin{array}{l}\chi^{2}=24.6 \\
p=.003\end{array}$ & Beta & Wald & $e^{b}$ & $p$ \\
\hline \multirow{2}{*}{$\begin{array}{l}\text { Dependent } \\
\text { variables }\end{array}$} & Overoptimism $=1$ & -1.419 & 5.038 & & .025 \\
\hline & Overoptimism $=2$ & -.193 & .095 & & .759 \\
\hline \multirow{9}{*}{ 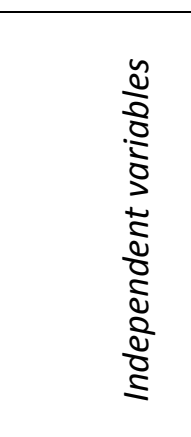 } & Financial literacy level & -.464 & 6.850 & .629 & $.009 * * *$ \\
\hline & Gender & -.247 & 1.404 & .781 & .236 \\
\hline & Marital status & .659 & 12.473 & 1.933 & $.000 * * *$ \\
\hline & Age & .799 & 2.439 & 2.223 & .118 \\
\hline & Education & .079 & .187 & 1.082 & .666 \\
\hline & Investment experience & -.334 & 3.267 & .716 & $.071^{*}$ \\
\hline & Source of financial info & .129 & .493 & 1.138 & .483 \\
\hline & Self-assessed literacy1 & -.078 & .120 & .925 & .729 \\
\hline & Self-assessed literacy2 & -.232 & .503 & .793 & .478 \\
\hline
\end{tabular}

Note: ${ }^{* * *} \mathrm{p} \leq 0.01 ;{ }^{* *} 0.01<\mathrm{p} \leq 0.05 ;{ }^{*} 0.05<\mathrm{p} \leq 0.10$ 
Table A2: Ordinal Regression Results for Illusion Of Control

\begin{tabular}{|c|c|c|c|c|c|}
\hline & $\begin{array}{c}\chi^{2}=29.982 \\
p=.000\end{array}$ & Beta & Wald & $e^{b}$ & $p$ \\
\hline Dependent & Illusion of control = 1 & -1.801 & 8.328 & & .004 \\
\hline variables & Illusion of control $=2$ & -.617 & .993 & & .319 \\
\hline & Financial literacy level & .185 & 1.259 & 1.203 & .262 \\
\hline$\stackrel{\tilde{a}}{2}$ & Gender & -.792 & 17.005 & .453 & $.000 * * *$ \\
\hline .00 & Marital status & .295 & 3.015 & 1.343 & $.082 *$ \\
\hline$\overline{\bar{s}}$ & Age & .102 & .039 & 1.107 & .843 \\
\hline$\tilde{\Sigma}$ & Education & -.164 & .933 & .849 & .334 \\
\hline$\frac{0}{5}$ & Investment experience & -.086 & .254 & .918 & .615 \\
\hline$\frac{2}{2}$ & Source of financial info & .020 & .014 & 1.020 & .905 \\
\hline ฮ̊ & Self-assessed literacy1 & -.047 & .050 & .954 & .824 \\
\hline & Self-assessed literacy2 & -.455 & 2.173 & .634 & .140 \\
\hline
\end{tabular}

Note: ${ }^{* * *} \mathrm{p} \leq 0.01 ; * * 0.01<\mathrm{p} \leq 0.05 ; * 0.05<\mathrm{p} \leq 0.10$

Table A3: Ordinal Regression Results for Overconfidence

\begin{tabular}{|c|c|c|c|c|c|}
\hline & $\begin{array}{c}\chi^{2}=62.404 \\
p=.000\end{array}$ & Beta & Wald & $e^{B}$ & $p$ \\
\hline \multirow{2}{*}{$\begin{array}{l}\text { Dependent } \\
\text { variables }\end{array}$} & Overconfidence $=1$ & -2.196 & 12.502 & & .000 \\
\hline & Overconfidence $=2$ & -.969 & 2.475 & & .116 \\
\hline \multirow{9}{*}{ 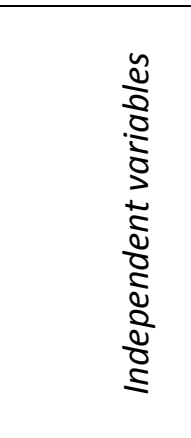 } & Financial literacy level & .533 & 10.359 & 1.704 & $.001 * * *$ \\
\hline & Gender & -.531 & 7.611 & .588 & $.006 * * *$ \\
\hline & Marital status & .457 & 7.230 & 1.579 & $.007 * * *$ \\
\hline & Age & .323 & .410 & 1.381 & .522 \\
\hline & Education & .025 & .023 & 1.025 & .881 \\
\hline & Investment experience & -.250 & 2.150 & .779 & .143 \\
\hline & Source of financial info & .026 & .024 & 1.026 & .878 \\
\hline & Self-assessed literacy1 & -.413 & 3.975 & .662 & $.046^{* *}$ \\
\hline & Self-assessed literacy2 & -1.538 & 22.335 & .215 & $.000 * * *$ \\
\hline
\end{tabular}

Note: ${ }^{* * *} \mathrm{p} \leq 0.01 ;{ }^{* *} 0.01<\mathrm{p} \leq 0.05 ; * 0.05<\mathrm{p} \leq 0.10$ 
Table A4: Ordinal Regression Results for Confirmation

\begin{tabular}{|c|c|c|c|c|c|}
\hline & $\begin{array}{c}\chi^{2}=25.143 \\
p=.003\end{array}$ & Beta & Wald & $e^{B}$ & $p$ \\
\hline \multirow{2}{*}{$\begin{array}{l}\text { Dependent } \\
\text { variables }\end{array}$} & Confirmation $=1$ & -1.866 & 6.464 & & .011 \\
\hline & Confirmation $=2$ & -.493 & .461 & & .497 \\
\hline \multirow{9}{*}{ 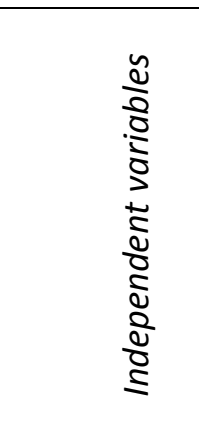 } & Financial literacy level & -.719 & 12.796 & .487 & $.000 * * *$ \\
\hline & Gender & -.01 & .002 & .990 & .966 \\
\hline & Marital status & -.121 & .352 & .886 & .553 \\
\hline & Age & .443 & .524 & 1.557 & .469 \\
\hline & \begin{tabular}{|l|} 
Education \\
\end{tabular} & .197 & .909 & 1.218 & .340 \\
\hline & Investment experience & -.008 & .001 & .992 & .970 \\
\hline & Source of financial info & .151 & .509 & 1.163 & .476 \\
\hline & Self-assessed literacy1 & -.204 & .617 & .815 & .432 \\
\hline & \begin{tabular}{|l|} 
Self-assessed literacy2 \\
\end{tabular} & .665 & 3.881 & 1.944 & $.049 * *$ \\
\hline
\end{tabular}

Note: ${ }^{* * *} \mathrm{p} \leq 0.01 ;{ }^{* *} 0.01<\mathrm{p} \leq 0.05 ;{ }^{*} 0.05<\mathrm{p} \leq 0.10$

Table A5: Ordinal Regression Results for Cognitive Dissonance

\begin{tabular}{|c|c|c|c|c|c|}
\hline & $\begin{array}{c}\chi^{2}=18.535 \\
p=.029\end{array}$ & Beta & Wald & $e^{B}$ & $p$ \\
\hline \multirow{2}{*}{$\begin{array}{l}\text { Dependent } \\
\text { variables }\end{array}$} & Cognitive dissonance $=1$ & -2.310 & 12.231 & & .000 \\
\hline & Cognitive dissonance $=2$ & -.966 & 2.18 & & .140 \\
\hline \multirow{9}{*}{ 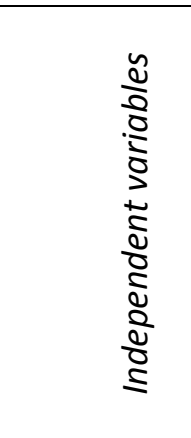 } & Financial literacy level & .397 & 5.566 & 1.487 & $.018^{* *}$ \\
\hline & Gender & -.089 & .202 & .915 & .653 \\
\hline & Marital status & -.347 & 4.190 & .707 & $.041^{* *}$ \\
\hline & Age & -.185 & .111 & .831 & .739 \\
\hline & Education & .000 & .000 & 1.000 & .999 \\
\hline & Investment experience & -.350 & 4.065 & .705 & $.044^{* *}$ \\
\hline & Source of financial info & -.114 & .429 & .892 & .512 \\
\hline & Self-assessed literacy1 & -.111 & .262 & .895 & .609 \\
\hline & Self-assessed literacy2 & -.194 & .402 & .824 & .526 \\
\hline
\end{tabular}

Note: ${ }^{* * *} \mathrm{p} \leq 0.01 ;{ }^{* *} 0.01<\mathrm{p} \leq 0.05 ;{ }^{*} 0.05<\mathrm{p} \leq 0.10$ 
Table A6: Ordinal Regression Results for Representativeness

\begin{tabular}{|c|c|c|c|c|c|}
\hline & $\begin{array}{c}\chi^{2}=16.710 \\
p=.053\end{array}$ & Beta & Wald & $e^{6}$ & $p$ \\
\hline Dependent & Representativeness $=1$ & -2.740 & 13.536 & & .000 \\
\hline variables & Representativeness $=2$ & -1.384 & 3.565 & & .059 \\
\hline & Financial literacy level & -.547 & 6.818 & .579 & $.009 * * *$ \\
\hline 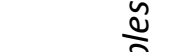 & Gender & .060 & .055 & 1.062 & .815 \\
\hline 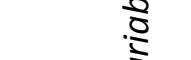 & Marital status & -.075 & .124 & .928 & .725 \\
\hline $\bar{g}$ & Age & .769 & 1.638 & 2.158 & .201 \\
\hline$\frac{\tilde{L}}{d}$ & Education & .422 & 3.883 & 1.525 & $.049 * *$ \\
\hline$\frac{0}{1}$ & Investment experience & -.285 & 1.697 & .752 & .193 \\
\hline$\stackrel{2}{2}$ & Source of financial info & .037 & .028 & 1.038 & .867 \\
\hline פ̊ & Self-assessed literacy1 & -.454 & 3.201 & .635 & $.074 *$ \\
\hline & Self-assessed literacy2 & -.505 & 1.838 & .604 & .175 \\
\hline
\end{tabular}

Note: ${ }^{* * *} \mathrm{p} \leq 0.01 ; * * 0.01<\mathrm{p} \leq 0.05 ; * 0.05<\mathrm{p} \leq 0.10$

Table A7: Ordinal Regression Results for Framing

\begin{tabular}{|c|c|c|c|c|c|}
\hline & $\begin{array}{c}\chi^{2}=32.420 \\
p=.000\end{array}$ & Beta & Wald & $e^{B}$ & $p$ \\
\hline \multirow{2}{*}{$\begin{array}{l}\text { Dependent } \\
\text { variables }\end{array}$} & Framing $=1$ & -1.866 & 7.730 & & .005 \\
\hline & Framing $=2$ & -.724 & 1.178 & & .278 \\
\hline \multirow{9}{*}{ 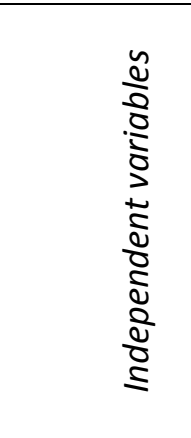 } & Financial literacy level & .511 & 9.106 & 1.667 & $.003^{* * *}$ \\
\hline & Gender & -.600 & 9.617 & .549 & $.002^{* * *}$ \\
\hline & Marital status & .011 & .004 & 1.011 & .948 \\
\hline & Age & -.277 & .242 & .758 & .623 \\
\hline & Education & .244 & 2.040 & 1.276 & .153 \\
\hline & Investment experience & -.140 & .642 & .869 & .423 \\
\hline & Source of financial info & .112 & .419 & 1.119 & .517 \\
\hline & Self-assessed literacy 1 & .150 & .471 & 1.162 & .492 \\
\hline & Self-assessed literacy2 & -.456 & 2.031 & .634 & .154 \\
\hline
\end{tabular}

Note: ${ }^{* * *} \mathrm{p} \leq 0.01 ;{ }^{* *} 0.01<\mathrm{p} \leq 0.05 ;{ }^{*} 0.05<\mathrm{p} \leq 0.10$ 
Table A8: Ordinal Regression Results for Loss Aversion

\begin{tabular}{|c|c|c|c|c|c|}
\hline & $\begin{array}{c}\chi^{2}=25.024 \\
p=.003\end{array}$ & Beta & Wald & $e^{b}$ & $p$ \\
\hline Dependent & Loss aversion $=1$ & .041 & .005 & & .946 \\
\hline variables & Loss aversion $=2$ & 1.284 & 4.391 & & .036 \\
\hline & Financial literacy level & .499 & 8.991 & 1.647 & $.003 * * *$ \\
\hline 气 & Gender & -.186 & .909 & .830 & .340 \\
\hline$\frac{0}{0}$ & Marital status & .156 & .854 & 1.169 & .356 \\
\hline $\bar{\jmath}$ & Age & 1.364 & 7.192 & 3.912 & $.007^{* * *}$ \\
\hline 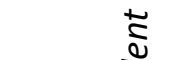 & Education & .272 & 2.622 & 1.313 & .105 \\
\hline$\frac{1}{0}$ & Investment experience & -.040 & .054 & .961 & .816 \\
\hline$\frac{\tilde{a}}{2}$ & Source of financial info & -.053 & .095 & .948 & .758 \\
\hline$\stackrel{8}{\Xi}$ & Self-assessed literacy1 & -.178 & .691 & .837 & .406 \\
\hline & Self-assessed literacy2 & -.129 & .188 & .879 & .665 \\
\hline
\end{tabular}

Note: ${ }^{* * *} \mathrm{p} \leq 0.01 ;{ }^{* *} 0.01<\mathrm{p} \leq 0.05 ;{ }^{*} 0.05<\mathrm{p} \leq 0.10$ 
This Page Intentionally Left Blank 